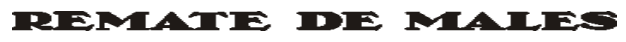

Campinas-SP, v.38, n.2, pp. 703-725, jul./dez. 2018

\title{
Escrever de volta: Anne Carson, EMILY DiCKINSON
}

\author{
Helena Franco Martins ${ }^{1}$
}

\begin{abstract}
Resumo: Anne Carson é poeta, ensaísta, tradutora e professora de letras clássicas. Uma das forças reconhecidas de sua obra publicada é o transbordamento singular que promove entre atos de escrita que costumam se distribuir por esses diferentes ofícios. Com uma liberdade e uma exatidão improváveis, misturam-se ali poesia, tradução, ensaio, escólio, crítica literária, conferência, libreto, entrevista e assim por diante. É de fato uma obra que corporifica de maneira admirável a tão falada reciprocidade que une o escrever, o ler e o traduzir. Proponho aqui uma reflexão pontual sobre os modos como esse enlace se dá em Autobiography of Red: A Novel in Verse. Exploro a hipótese de que uma forma quase paradoxal de atenção aos fatos preside os gestos de leitura, tradução e escrita poética que Carson encena e imbrica nesse seu inclassificável livro. Dou ênfase especial ao estatuto do poema de Emily Dickinson que a autora traz ali como epígrafe. É com uma tradução desse poema que abro a minha reflexão aqui.

Palavras-chave: Anne Carson; Emily Dickinson; tradução.
\end{abstract}

1 Professora da Pontifícia Universidade Católica do Rio de Janeiro e bolsista de produtividade nível 2 do CNPq: <lena@puc-rio.br>. 
The reticent volcano keeps

His never slumbering plan;

Confided are his projects pink

To no precarious man.

If nature will not tell the tale Jehovah told to her,

Can human nature not survive

Without a listener?

Admonished by her buckled lips

Let every babbler be.

The only secret people keep

Is Immortality.
Guarda o vulcão reticente

Seu plano sempre desperto;

Jamais seus róseos intentos

Confia ao homem incerto.

Se a natureza não espalha

O que lhe contou Jeová,

Vive a natureza humana

Sem quem a venha escutar?

Sua boca muda interpele Quem tagarela à vontade. Guardamos um só segredo: A imortalidade.

(Emily Dickinson, 196o, n. 1748)²

2 São minhas todas as traduções sem outra indicação. Utiliza-se aqui a edição de Thomas H. Johnson (1960, p. 708), The Complete Poems of Emily Dickinson. Além disso, mantive a praxe de referência aos poemas de E.D. via numeração padrão, e não por página. 


\section{A CIRCUNSTÂNCIA DA TRADUÇÃO}

É com um poema intitulado "a tarefa do tradutor de antígone" que Anne Carson prefacia Antigonick, sua (polêmica) tradução da tragédia de Sófocles. ${ }^{3}$ Ao evocar e provocar assim "A tarefa do tradutor", título do famoso ensaio de Walter Benjamin, Carson sinaliza com algum humor o que parece ser um traço importante na sua prática tradutória: uma atenção ao que há de volátil na tarefa, à sua natureza circunstancial - um interesse por aquilo que, nos atos de tradução, não se deixa reduzir a qualquer imperativo geral. A tarefa do tradutor de Antígone - que é, segundo lemos ao final daquele poema-prefácio, "jamais deixar que [Antígone] perca seus gritos"4 - não seria igual à tarefa do tradutor de uma outra tragédia de Sófocles ou de Eurípedes, nem equivaleria àquela do tradutor de fragmentos de Safo ou de Estesícoro ou de Álcman. A variedade espantosa de procedimentos e condutas com que Carson traduz esses e outros autores clássicos talvez encontre raiz nesse compromisso radical com a noção de que cabem ao tradutor diferentes tarefas, irredutíveis a-fazeres.

E sabe-se que o fazer tradutório, longe de configurar uma atividade paralela, atravessa a escrita poética de Anne Carson, tendo ali um papel constitutivo. De fato, sua obra publicada é conhecida pelo singular transbordamento de fronteiras que promove, não apenas no que tange à tradução, mas também a outras formas de escrita ligadas às diferentes profissões que exerce (além de poeta e tradutora, Carson é ensaísta e professora de letras Clássicas). ${ }^{5}$ Com uma liberdade e uma exatidão improváveis, misturam-se ali poesia, tradução, ensaio, escólio, crítica literária, conferência, libreto, entrevista e assim por diante. É uma obra que encena e corporifica de maneira admirável a hoje tão falada reciprocidade que une os atos de escrever, ler e traduzir: nas linhas de Anne Carson, convivem em atraente oxímoro, uma assinatura inconfundível e um senso agudo de que, como diz Jacques Derrida, toda língua, toda escrita, "é sempre do outro, vem do outro, é $a$ vinda do outro". ${ }^{6}$

3 No original: "the task of the translator of antigone" (CARSON, 2015b, p. 3).

4 "[...] cara Antígone,/ entendo que a tarefa do tradutor é/ jamais deixar que perca seus gritos" [dear Antigone, /I take it as the task of the translator/ to forbid that you should ever lose your screams] (CARSON, 2015b, p. 6).

5 Sobre esses transbordamentos, ver, por exemplo, a coletânea editada por Wilkinson (2015).

6 “[La langue] est à l'autre, venue de l'autre, la venue de l'autre” (DERRIDA, 1996, p. 127). 
Proponho aqui uma reflexão breve sobre os modos como o enlace entre escrita, leitura e tradução acontece em Autobiography of Red: A Novel in Verse, livro que Carson publica em 1998. Se, para isso, parto da tradução do poema n. 1748 de Emily Dickinson, é porque nesse livro, entre muitas outras coisas, Anne Carson responde criadoramente ao acontecimento desse poema - à "vinda" desse outro, diríamos com Derrida. O indício mais óbvio disso (de modo algum o único) é que o poema vem ao livro como epígrafe, retornando também de forma explícita em seus capítulos finais, com ênfase no motivo do vulcão.

No ato de tradução com que respondo à chamada deste volume de Remate de Males, busquei então me haver com uma tarefa bastante específica: a tarefa do tradutor do poema no. 1748 de Emily Dickinson, epígrafe de Autobiography of Red, de Anne Carson. A versão que compus em português é de fato inteiramente circunstanciada - impactada - pela leitura que faço de Anne Carson lendo Emily Dickinson nesse livro em particular. Dito ainda de outra forma: traduzi o poema de Dickinson imaginando-o como parte de uma tradução virtual maior, a tradução de Autobiography of Red.

A hipótese mais geral que gostaria de avançar aqui poderia ser formulada assim: os múltiplos gestos de escrita, leitura e tradução que Anne Carson encena e imbrica nesse seu inclassificável livro se deixam atravessar por uma forma particular - quase paradoxal - de atenção aos fatos. Buscarei mostrar que, lido na circunstância deste livro, o poema de Dickinson empresta forças a essa atenção - reclama-a.

Para começar, então: que tipo de circunstância se arma no livro que o poema de Dickinson ajuda a armar?

\section{UM LIVRO-MONSTRO}

Autobiography of Red: A Novel in Verse $e^{7}$ é um livro que retorna ao mito de Gerião, personagem que nos chega mais conhecido como coadjuvante de Héracles em seu décimo trabalho. Monstro gigante que tem, a depender da fonte, três corpos, seis braços e seis asas, ele é o dono do cobiçado gado vermelho que cabe a Héracles capturar em sua expedição à ilha da Erítia. Anne Carson se interessa por uma outra versão da história, menos

7 Autobiografia do Vermelho: um Romance em Verso. Para referenciar passagens citadas desse livro, utilizarei doravante a abreviação "AoR", seguida do número da página no original. 
conhecida - aquela do poeta grego Estesícoro de Hímera (c. 640-556 a.C.), que, segundo indica o que sobreviveu de sua Gerioneida, teria recontado o mito do ponto de vista do monstro.

O livro de Carson se inicia com uma espécie de proêmio em que se apresentam aspectos da vida e da obra de Estesícoro. Seguem-se então a tradução de um conjunto de fragmentos atribuídos à Gerioneida e três pequenos apêndices ao proêmio. Chega-se por fim à parcela maior do livro, esta que, epigrafada com o poema de Emily Dickinson, intitula-se "Autobiography of Red: A Romance" - e que, de novo, nos trará um Gerião e um Héracles, agora personagens de nossos tempos, vivendo um caso de amor. $^{8}$

Descrito de forma assim ligeira, o livro parece compor-se de uma sequência de escritos de gêneros distintos: um ensaio filológico-crítico e uma tradução precederiam um escrito literário autoral. Mas o que de fato experimentamos ao entrar no jogo entre essas três "partes" é uma extensão daquilo que já se abrevia no título do livro, um título no qual gêneros - autobiografia, romance e poesia - são ao mesmo tempo nomeados e imbricados. Observemos de saída então que, como quer que a reciprocidade entre atos de leitura, tradução e escrita compareça nessa obra de Anne Carson, estará envolvido um gesto de encená-los como atos a um tempo distintos e misturados. (Um pouco como Borges, diriam alguns; eu diria que bem pouco).

Por seus modos singulares, o estranho livro de Carson se comporta talvez como um monstro: três (ou mais) corpos agitando-se em separado, mas movendo-sejuntos, arrastando um ao outro em direções imprevisíveis, democraticamente plantados num mesmo quadril.

Mas voltemos ainda ao título: ele perturba e atrai também, é claro, pelo protagonista que ali se nomeia para essa autobiografia que é romance em verso: "Red". Ficamos talvez suspensos entre uma antecipação mais pacífica do que vem pela frente, lembrando que Red é um apelido relativamente comum em inglês, ${ }^{9}$ e a surpresa gerada pela atribuição da

8 É oportuno atentar para a variação desse título interno em relação àquele da capa: aqui temos "A Romance" ao passo que lá temos "A Novel in Verse". "Novel" se traduz no mais das vezes por "romance" em português; o termo inglês "romance" admite a tradução cognata, mas, remetendo também à esfera dos contos medievais, tende a se aplicar como rótulo genérico para obras que tratam o amor de forma sentimental, idealizada. Para uma reflexão sobre o jogo entre "novel" e "romance" em face de suas contrapartes na antiguidade, ver Carson (2015a, pp. 77-82).

9 Isso implicaria talvez alguma perda em sua tradução por "Vermelho" no português. 
autobiografia a um domínio extra-humano, a estranha noção de que uma cor possa ter uma autobiografia. Se chegamos a esse livro já como leitores cativos de Anne Carson, isso não surpreenderá tanto: teremos, com sorte, sido iniciados numa escrita que cultiva a suspensão como um valor e, mais ainda, que descobre nela uma forma de exatidão - algo talvez próximo à "exata existência atual do infinito" de que fala Jean-Luc Nancy (2013, p. 420) em suas reflexões sobre o fazer a/da poesia.

Seguiremos assim, então, suspensos e favoravelmente perturbados quando, ao abrirmos o livro, nos defrontarmos com o título de sua primeira seção, o proêmio acima aludido: "Carne vermelha: que diferença fez Estesícoro?". ${ }^{\circ}$

O vermelho é agora também o da carne: uma pergunta relativamente bem-comportada, compatível com um escrito de vocação crítica sobre a obra de um antigo poeta, é atirada ao leitor como um naco de carne vermelha, num assalto que não nos furtaremos em reconhecer já aí, no título do ensaio introdutório, como francamente enigmático - poético. (Um naco de carne para distrair os cães e permitir a entrada?)."

Seja como for, não há dúvida de que o proêmio que se desdobra sob o enigma desse título é didático e informativo. Junto a seus apêndices, traz muitos elementos que lhe dão o ar de um estudo acadêmico típico das letras clássicas: o leitor será informado que Estesícoro viveu entre refugiados e falou um dialeto misto (entre Calcídico e Dórico); saberá das obras que o poeta escreveu e, destas, as que sobreviveram na íntegra ou fragmentariamente; será remetido a testimonia (de Suídas, Isócrates e Platão) e a citações da fortuna crítica da antiguidade (Longino, Dionísio de Halicarnasso, Hermógenes); conhecerá também algumas particularidades sobre a Gerioneida, coleção ali descrita como "a obra prima” de Estesícoro, que nos chega em esparsos fragmentos (AoR 6). No entanto, esse erudito (e interessante) aparato filológico-crítico nunca deixa de dividir a cena com certas disruptivas e produtivas liberdades.

Para começar, não nos sai da cabeça que é sob o título "carne vermelha", num livro intitulado Autobiografia do vermelho, que recebemos todas essas informações - os títulos pairam sobre a leitura combinando perplexidades

\footnotetext{
10 "Red Meat: What Difference did Stesichoros Make?" (AoR 3 ).

11 Poderá nos ocorrer também que a expressão "red meat" é usada idiomaticamente em referência a formas agressivas de retórica, notadamente em contextos políticos; e que pode ainda, claro, indicar: o cerne de uma questão, o aspecto mais substantivo de algo. Ficamos suspensos.
} 
e acentuando intensidades, à medida que vamos conhecendo mais coisas sobre o mito do monstro vermelho que guardava seu cobiçado gado vermelho na vermelha ilha de Erítia. Além disso, a maneira como se apresentam ali o poeta e sua obra faz com que a dicção acadêmica conviva o tempo todo com atrevidas linhas de fuga, movimentos que surpreendem pelo humor, pelo teor desconcertante, pelo que deixam apenas sugerido, pelo que têm de poético.

Em provocação risonha às balizas habituadas do cânone ocidental, Estesícoro é, por exemplo, apresentado como alguém que "veio depois de Homero e antes de Gertrude Stein, intervalo difícil para um poeta" (AoR 3). ${ }^{12}$ Seu talento para criar adjetivos e epítetos diferentes daqueles que Homero fixara "para consumo épico" é louvado como uma verdadeira operação poético-ontológica:

[Os adjetivos são] pequenos mecanismos importados cuja tarefa é atar tudo o que existe no mundo a seu lugar particular. São as travas do ser. [...] Sem que ninguém pudesse explicar por que, Estesícoro pôs-se a soltar as travas. Estesícoro liberou o ser. E todas as substâncias saíram flutuando. ${ }^{13}$

Em linhas igualmente perturbadoras, agora mais especificamente dedicadas aos fragmentos que sobreviveram da Gerioneida, lemos: é "como se Estesícoro tivesse composto um poema substancial narrativo, e depois o tivesse rasgado em pedaços, que então enterrou numa caixa junto com algumas letras de música, notas de palestras e pedaços de carne". ${ }^{4}$ Pedaços de carne?

Atravessado por outras declarações desconcertantes, sugestivas e cheias de humor como essas, o proêmio se deixa ler numa chave paródica, espécie de retorno (auto)irônico ao aparato filológico e às estratégias da academia - ironia que, de fato, é às vezes levada a paroxismos, como no caso do Apêndice $C$, dedicado a esclarecer de vez a questão da cegueira de Estesícoro: teria Helena castigado Estesícoro coma perda da visão, ofendida

12 "He came after Homer and before Gertrude Stein, a difficult interval for a poet." A voz de Gertrude Stein atravessa o livro com grande ressonância, assim como a de Emily Dickinson. Isso mereceria um outro artigo.

13 "[...] small imported mechanisms are in charge of attaching everything in the world to its place in particularity. They are the latches of being. [...] For no reason that anyone can name, Stesichoros began to undo the latches. Stesichoros released being. All the substances in the world went floating up" (AoR 4-5).

14 "[...] as if Stesichoros had composed a substantial narrative poem then ripped it to pieces and buried the pieces in a box with some song lyrics and lecture notes and scraps of meat. The fragment numbers tell you roughly how the pieces fell out of the box" (AoR 6-7). 
pelos epítetos vilipendiosos que este lhe dispensara? Teria Estesícoro recuperado a visão depois de escrever-lhe uma Palinódia, retratando-se? Numa sequência encadeada de 21 enunciados condicionais e disjuntivos, a lógica supostamente infalível do terceiro excluído é submetida à mais cômica e anárquica deriva, emboscada por todos os lados com reversões, circularidades, anacronismos, comentários incidentais e assim por diante (AoR 18-20). Mas nem mesmo aí, onde o tom paródico se faz tão evidente, parece possível reduzir a uma chave a riqueza monstruosa dessa escrita de tantos corpos.

O proêmio é ao mesmo tempo paródia da academia e estudo acadêmico sério, ao mesmo tempo ensaio e poesia, crítica literária e comentário metaficcional - é ao mesmo tempo um preâmbulo à obra e a obra desde já (desde sempre?) começada.

Veremos agora que algo bem semelhante acontece na seção seguinte, aquela que traz as traduções para os fragmentos compostos por Estesícoro em sua Gerioneida.

\section{A TAREFA DO TRADUTOR DA GERIONEIDA}

Em "Variations on the Right to Remain Rilent", Anne Carson nos diz a certa altura que a catástrofeé uma reposta que se dá ao clichê-uma resposta de gênio a essa sensação de fúria contra o clichê que todos experimentamos em algum momento. Diz ainda que é uma resposta porque o clichê é sempre uma pergunta. Recorremos ao clichê, ela nos diz, "porque é mais fácil do que tentar inventar alguma coisa nova”; e, no entanto, implícita no clichê, já está sempre a pergunta: "Já não sabemos o que achamos disso? Não há uma fórmula que usamos para isso?" (CARSON, 2016, [s.p.]). Ao final desse ensaio, que versa entre outras coisas sobre a "benevolência" da tradução nas investidas contra o clichê, Carson propõe um exercício: tomar um pequeno fragmento da lírica grega e traduzi-lo inúmeras vezes “usando as palavras erradas". É o que ela faz com um poema e Íbico (fr. 286). A uma primeira tradução do original, acrescenta outras cinco, com as "palavras erradas" de: (i) "Woman's Constancy”, de John Donne; (ii) Arquivo de Bertolt Brecht no FBI, \#10o-67077; (iii) Endgame, de Samuel Beckett; (iv) Conversations with Kafka, de Gustav Janouch; e (v) Manual do usuário de meu novo Microondas Emerson 10ooW. A autora descreve essa experiência como "uma espécie de gagueira" - não se trata nem de traduzir nem de des-traduzir [untranslating], mas antes de "catastrofizar a tradução" (CARSON, 2016, [s.p.]). 
Como quer que pensemos esse exercício em particular, é possível que a ampla e inventiva gama de estratégias que, no conjunto dos escritos de Anne Carson, atendem pelo nome de tradução provenha de um desejo de responder ao clichê da tradução (já não sabemos o que pensamos sobre isso?) - por um desejo de catastrofizá-la. Seus experimentos mais catastróficos têm lhe rendido críticas e despertado polêmicas, mesmo entre seus entusiasmados admiradores, supostamente isentos de zelos e idealizações essencialistas para com a fonte, o original.

É o caso de George Steiner, na resenha crítica que escreve para Antigonick. A ficha catalográfica do livro diz que o autor é Sófocles e a tradutora é Anne Carson, mas Steiner arranha com aspas a palavra "tradução" no título da resenha: pois, para ele, Carson teria virado as costas para Sófocles ao invés de celebrá-lo, dando afinal ao mundo "um objet trouvé, um artefato pós-moderno ou Dada, um acontecimento muito ao norte [...] do radiante e moralmente complexo texto original" (STEINER, 2012, [s.p.]). ${ }^{5}$ Para Steiner, seriam no geral condescendentes, gratuitamente vulgares e empobrecedoras as estratégias tradutórias de Carson nesse caso - procedimentos que incluem trazer para a tragédia de Sófocles barcos a motor e bicicletas, gírias e coloquialismos modernos, referências a grandes leitores e leituras da peça (Hegel e Brecht), menções a outros artistas (Beckett, Virginia Woolf), isso para não falar das modulações abreviadas das falas originais, ou do acréscimo de falas (aí destacando-se um monólogo poético para Eurídice) e mesmo a inclusão de um personagem, o silencioso Nick. As ousadias proliferam.

Acredito que Carson cumpre (espetacularmente) em Antigonick a tarefa tradutória que nomeia para si: impedir que Antígone perca seus gritos. E reconheço ali, entre muitas outras coisas, o resplendor e a complexidade moral que, para Steiner, ficam ausentes. No entanto, para efeito de comparação com o caso que nos toca mais de perto, mais importante do que avaliar a pertinência da crítica de Steiner, é registrar que, qualquer que seja o valor que se lhe atribua, Antigonick é uma obra em que tradução, leitura e escrita imbricam-se com singular reciprocidade

\footnotetext{
15 Steiner resenha a primeira edição do livro, publicada pela New Directions Books em 2012 - composta sob forma de história em quadrinhos, com ilustrações de Bianca Stone e blocos de textos escritos a mão em letra de forma; o projeto contou também com a colaboração de Robert Currie. Muito se poderia dizer sobre a radicalidade desse formato; neste artigo, no entanto, concentro-me apenas no texto da tradução e me valho de uma edição posterior, de 2015, que o traz avulso, acrescido do poema-prefácio citado acima.
} 
- eu diria que o que há de singular aí reside, em parte, na forma como Carson cria uma espécie de dramaturgia poética da reciprocidade.

Que a tradução é um ato originalmente poético e que é também uma forma privilegiada de leitura já sabemos pelo menos desde Benjamin mas Carson faz disso uma experiência dramática, performa-a. Fiquemos com um exemplo apenas, o da primeira fala de Creonte:

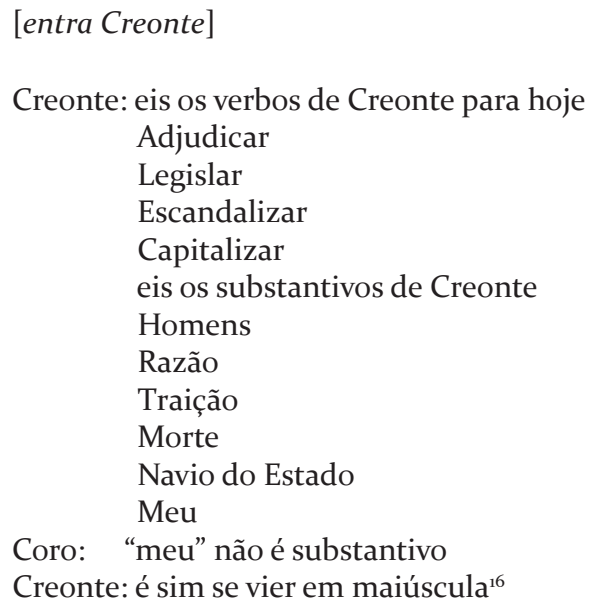

Atribuiremos a Sófocles essas palavras se formos citá-las de acordo com a ficha catalográfica - e, no entanto, é claro que, para qualquer leitor que conheça minimamente o texto original, isso que aqui se oferece como tradução gritará alto: sou também leitura, sou poesia - sou um (engraçado) monstro de pelo menos três corpos. A reciprocidade entre traduzir, ler e escrever não corre no subterrâneo: é ela mesma encenada.

Quis dar esse exemplo para que, num cotejo com o que acontece na Gerioneida, fiquemos com uma pequena amostra da radical diversidade de procedimentos com que Carson, sempre sensível à volatilidade da tarefa do tradutor, imbrica o traduzir, o ler e o escrever. E o que acontece, então, no caso da tradução da Gerioneida, assim como ela vem ao mundo na particular circunstância de Autobiography of Red? Nas páginas finais do proêmio, lemos:

\footnotetext{
16 "Kreon: Here are Kreon's verbs for today/ Adjudicate/ Legislate/ Scandalize/ Capitalize/ here are Kreon's nouns/ Men/ Reason/ Treason/ Death/ Ship of State/ mine/ Chorus: 'mine' isn't a noun/ Kreon: it is if you capitalize it" (SÓFOCLES, 2015, p. 14). Perde-se em português o jogo possível com a palavra inglesa "capitalize", que pode significar "capitalizar" e "pôr em letra maiúscula".
} 
O leitor poderá responder por si mesmo à pergunta "Que diferença fez Estesícoro?", ao examinar a sua obra-prima. Seguem-se alguns de seus principais fragmentos. Se achar o texto difícil, não estará sozinho. O tempo foi impiedoso com Estesícoro. [...] Os restos de papiro [...] ocultam tanto quanto revelam. ${ }^{17}$ (AoR 6, grifo meu)

Encena-se um convite explícito: estimado leitor, vá às fontes, leia os fragmentos traduzidos a seguir. O leitor assente e passa então ao capítulo intitulado "Carne vermelha: fragmentos de Estesícoro". A fé na antiguidade das fontes será logo provocada por uma invasão de anacronismos: nos fragmentos presumivelmente escritos no século VI a.C., o leitor dará com coisas como "taxi vermelho", "fim de semana" e "placa quente" (AoR 16, 17). Nisso a tradução da Gerioneida se assemelha à de Antígone e a outras de Carson. Mas há diferenças importantes: são gestos mais radicais, e talvez mais sutis, que vêm se acomodar sob o nome de tradução - no caso dos fragmentos de Estesícoro, que fazem sua aparição em Autobiography of Red. Dos 16 fragmentos ali reunidos, apenas dois se deixam reconhecer no cotejo com as fontes originais (o fragmento VII e o XIV; AoR 11, 13).

"Carson cria fragmentos de um poema inexistente sob a camuflagem da tradução", afirma peremptoriamente Bruce Beasley (2015) em estudo recente. Segundo sua leitura, ela nos estaria instando "a julgar um poeta antigo como se fosse um seguidor pós-moderno de Gertrude Stein" - e só nos restaria confirmar esse juízo, ao ler "poemas de Carson como se fossem de Estesícoro” (BEASLEY, 2015, p. 75). Para ele, os muitos críticos e leitores que aceitam como traduções os fragmentos de Estesícoro incorrem em uma espécie de logro - e passam assim ao largo "das complexidades, da força subversiva e dos modos profundamente paródicos" com que Carson estaria provocando "a autoridade dos especialistas e eruditos e a passividade da crítica” (p. 77). Ele não hesita enfim em apontar (e inclusive, na sequência do artigo, louvar) o que toma como uma astuta estratégia de Carson: esconder-se, camuflar propositalmente a sua autoria sob véu falso da tradução, com intenções crítico-paródicas.

Por razões já em partealudidas acima, parece-me mais uma vez redutora a leitura na chave exclusiva da paródia: Beasley, como eu, reconhece o que há de encenação na forma como a tradução faz a sua entrada no fluxo do

17 "You can answer for yourself the question 'What difference did Stesichoros make?' by considering his master piece. Some of its principal fragments are below. If you find the text difficult, you are not alone. Time has dealt harshly with Stesichoros [...] and papyrus scraps [...] withhold as much as they tell.”(AoR 6). 
livro - mas, ao atribuir ao expediente (apenas) uma espécie de astúcia crítica (excessivamente cerebral?), deixa talvez à sombra o que me parece ser um aspecto crucial: que essas invenções "mentirosas" são ao mesmo tempo formas genuínas de responder à tarefa do tradutor da Gerioneida.

É útil aqui então a pergunta direta: qual é essa tarefa para Carson? Já se disse que Estesícoro reconta o encontro de Gerião e Héracles do ponto de vista do monstro. O proêmio descreve assim essa mudança perspectiva:

Se Estesícoro tivesse sido um poeta mais convencional, teria talvez tomado o ponto de vista de Héracles e criado um relato eletrizante do triunfo da cultura sobre a monstruosidade. Em vez disso, o que os fragmentos remanescentes do poema de Estesícoro nos oferecem é uma fascinante amostra de cenas cruzadas, tão dignas quanto lamentáveis, segundo a experiência do próprio Gerião. (AoR $6)^{18}$

Aotriunfodeuma culturaunificada erefratáriaaosdesvioseàsaberrações, opõe-se à perspectiva do monstro. Mais importante que isso, a visada do monstro não opõe uma narrativa à outra - o que se passa é justamente que essa visada não se deixa integrar numa narrativa: dispersa--se, em vez disso, numa multiplicidade irresistível de cenas cruzadas. Um menino vermelho com seu cachorrinho; uma mãe em súplica; "planos intercalados de Héracles se aproximando, vindo do mar"; num clarão no céu, Deuses decidindo a sina infeliz; a batalha; "o momento em que tudo se desacelera e a flecha abre o crânio de Gerião"; "Héracles matando o cão com Seu famoso bastão" (AoR 6). A visada do monstro são muitas; Gerião é afinal mais de um corpo, mais de uma cabeça, mais de um par de olhos, muitos braços, asas.

A tarefa do tradutor dos fragmentos da Gerioneida teria talvez a ver com a preservação dessa visada múltipla, dispersa e cruzada - a impedir a perda dessa atenção multiplicada. Os fragmentos que nos são apresentados como traduções de Estesícoro honram essa tarefa de uma maneira, a meu ver, prodigiosa. Dois exemplos:

\section{IX: O registro de guerra de Gerião}

Gerião deitou-se no chão cobrindo os ouvidos O som

Dos cavalos como rosas queimadas vivas ${ }^{19}$

\footnotetext{
18 "If Stesichoros had been a more conventional poet He might have taken the point of view of Herakles and framed a thrilling account of the victory of culture over monstrosity. But instead the extant fragments of Stesichoros'offer a tantalizing cross section of scenes, both proud and pitiful, from Geryon's own experience" (AoR 6).

19 "IX. Geryon's war record// Geryon lay on the ground covering his ears The sound/ Of the horses like roses being burned alive" (AoR 12).
} 


\section{XIII: O bastão letal de Héracles}

O cãozinho vermelho nem viu sentiu Todos

Os eventos trazem um só ${ }^{\circ}$

Gerião, os cavalos, rosas queimadas, a guerra; o cão, o bastão, o golpe, a majestade da morte. A narrativa integrada - que poderia se insinuar, por exemplo, num título que promete um registro de guerra -, cede às cenas dispersas, surpreendentes: na guerra, Gerião está com os cavalos, com rosas que queimam; em outra parte, o cão em seu encontro com o bastão letal (Héracles não se vê). Ao ler os fragmentos, enfim, o leitor não acompanha propriamente uma história, a história de alguém - dispersa-se atento, entre acontecimentos, cenas, sensibilidades, está empenhado e concentrado nessa dispersão.

Que esses e outros fragmentos não encontrem âncora comprovada na Gerioneida não parece excluir a força do gesto tradutório aqui - dá-se a ver um impulso de traduzir não tanto o que Estesícoro escreveu, mas antes o que (se crê que) ele fez. A visão do logro calculado, defendida por Beasley, deixa isso de fora - e tende ainda a desconsiderar o fato de que, em suas encenações, Carson subverte ironicamente também a própria história "filológica" dos fragmentos (lembremos: é como se Estesícoro tivesse escrito uma história substancial e depois a tivesse rasgado em pedaços, enterrando-os todos numa caixa, junto com letras de música, anotações, pedaços de carne). Mais importante, o convite que se faz ao leitor para ir às fontes combina-se com provocações imediatas sobre o que há de construído e aleatório nas fontes: "os números dos fragmentos dizem mais ou menos como [aqueles estranhos componentes] caíram para fora da caixa”. O convite inclui ainda, por fim, uma exortação direta à participação criadora do leitor: "é claro que se pode continuar agitando a caixa. [...] Aqui. Agite”. ${ }^{21} \mathrm{O}$ papiro rasgado abre sempre a possibilidade de conjecturas sobre o material perdido. É como se Carson dissesse: todos os papiros vêm rasgados, e não há limite para as conjecturas.

Os fragmentos assim traduzidos e conjecturados encenam ainda de uma outra forma os laços mutuamente constitutivos entre tradução, leitura e escrita. Entre as muitas outras liberdades que, por amor à catástrofe, Carson se permite nesse caso, inclui-se o gesto de tornar

20 "XIII. Herakles' killing club// Little red dog did not see it he felt it All/ Events carry but one" (AoR 13).

21 "The fragment numbers tell you roughly how the pieces fell out of the box."; "You can of course keep shaking die box. [...] Here. Shake." 
porosos os limites entre as camadas de reapropriação do mito. Assim é que, por exemplo, no fragmento VII ("Fim de semana de Gerião") - um dos dois únicos que teriam derivado de fontes comprovadas -, Carson desenha uma cena de sedução com flashes num bar e num apartamento, o encontro de Gerião com um centauro que lhe prepara uma bebida, uma cena de elétrica culminância erótica: "Não foi uma abelha o que subiu por dentro da espinha de Gerião". ${ }^{22}$ Carson retém do fragmento original apenas o motivo mais geral: um centauro (no caso, Folo) prepara uma bebida para uma figura masculina (tudo indica que Héracles, não Gerião). ${ }^{23} \mathrm{O}$ escrito por começar já começou; o Gerião de Estesícoro já é o de Carson. Esses transbordamentos bilaterais entre as partes separadas pelas seções tradução e romance em verso alcançam muitos planos. Vejase, por exemplo, como o fragmento IX, citado acima, retorna no romance:

À noite na cama ele escutava a luz prateada das estrelas batendo contra o vidro da janela. Muitos

dos que ele tinha entrevistado para o projeto admitiam não ouvir os gritos das rosas

queimando vivas pelo sol a pino. Como cavalos, dizia Gerião para ajudar, como cavalos numa guerra. Não, balançavam as cabeças. (AoR 84) ${ }^{24}$

O romance de Carson inclui pois, também por esse caminho, a encenação explícita dos laços entre as formas de (re)escrita que mobiliza: o percurso duplo de retomada do mito é posto diante de nossos olhos - a reapropriação de Estesícoro é primeiro apresentada para ser depois, ela mesma, reapropriada. Mas, nos espelhamentos entre as duas partes, um movimento transborda no outro, sem se deixar presidir pela lógica da origem e do destino: e isso se manifesta não apenas no motivo onipresente da monstruosidade, assentado na figura de Gerião, não apenas no encontro e no embate com Hércules, nem apenas nos episódios ou cenas que, como essa do fragmento IX, retornam explicitamente - o jogo entre diferença e repetição se manifesta também nos próprios ademanes da escrita. Retornam no romance em verso as sequências de cenas dispersas, os títulos sugestivos, algo do ritmo, algo da forma de cortar os versos, algo da pontuação (não são idênticos mas há reciprocidade).

\footnotetext{
22 "Not a bee moved up Geryon's spine on the inside" (AoR 11).

23 Sobre isso ver Campbell (1991, p. 81).

24 "He lay on his bed at night listening to the silver light of stars crashing against/ the window screen. Most/ of those he interviewed for the science project had to admit they did not hear/ the cries of the roses/ being burned alive in the noonday sun. Like horses, Geryon would say helpfully,/ like horses in war. No, they shook their heads."
} 
Em entrevista a Eleanor Watchel (2014, [s.p.]), Anne Carson afirma que, em Autobiography, tinha incialmente começado a escrever um livro robusto em prosa, um livro para "ser lido nos aeroportos", mas que depois acabou chegando à forma fragmentária que vemos ilustrada na passagem citada acima, e que, do início ao fim, alterna, aos pares, versos mais longos e mais curtos. Teria primeiro escrito uma narrativa substancial que depois tratou de rasgar aos pedaços como Estesícoro? O jogo de cena se mantém também aqui. A entrevistadora pergunta se o romance entre Héracles e Gerião seria derivado da versão de Estesícoro. Ela responde que de jeito nenhum. Essa mudança não a impede de afirmar com convicção que, nesse livro, apenas contou a antiga história de Gerião, com base na versão de Estesícoro, alterando-a um pouco. “Um pouco?”, pergunta a entrevistadora incrédula. "Um tanto", ela responde” (WATCHEL; CARSON, 2014, [s.p.]).

Pois bem, passamos pelas primeiras seções: ensaio crítico, tradução, poesia, tudo, por assim dizer, na mesma carne (viva). Aí chegamos finalmente ao romance em verso, chegamos àquilo a que já havíamos chegado. Entramos pela porta de uma epígrafe.

\title{
AO VULCÃO RETICENTE (AOS FATOS)
}

Emily Dickinson, poema n. 1748: reproduzo aqui a minha tradução, por comodidade de leitura e também para deixar indicadas duas alternativas em relação às quais ainda hesito: ${ }^{25}$

\author{
Guarda o vulcão reticente \\ Seu plano sempre desperto; \\ Jamais seus róseos intentos \\ Confia ao homem incerto. \\ Se a natureza não espalha \\ O que lhe contou Jeová, \\ Vive a natureza humana \\ Sem quem a venha escutar? \\ Sua boca muda interpele \\ Quem tagarela à vontade. \\ Guardamos um só segredo: \\ A imortalidade. \\ / Se a natureza não revela \\ / Que sua mudez interpele
}

25 Agradeço imensamente a Paulo Henriques Britto e Caetano Galindo, que leram e comentaram versões anteriores. 
Chegamos ao poema de Dickinson envoltos na atmosfera do que vínhamos lendo: como epígrafe intercalada entre segmentos entre si tão porosos, ele se devolve às páginas anteriores, tanto quanto às posteriores; lê-as, deixa-se ler por elas.

A insistente "carnevermelha" eos "róseos intentos" irão possivelmente coalescer; sobrepõem-se, talvez, as imagens do magma debaixo da terra e da carne sob a pele. Divisamos no fundo do vulcão a carne viva do mundo e reconhecemos também o vulcanismo no corpo - o "Vesúvio em casa", diria Emily Dickinson em um outro poema que dá testemunho de seu conhecido amor pelos vulcões. ${ }^{26}$ Essa vizinhança entre vulcanismo, corpo e mundo é recorrente ao longo do romance em verso, por vezes de modo bem explícito:

Acho que sou alguém que nunca vai estar satisfeito,

disse Héracles. Gerião sentiu todos os seus nervos indo à superfície do corpo.

Como assim satisfeito?

Apenas - satisfeito. Não sei. Veio de baixo da estrada um som

de anzóis arranhando o fundo do mundo. ${ }^{27}$

O motivo dovulcão de fato prepondera; ea epígrafe de Emily Dickinson, sua figura e sua voz, retornam nesse âmbito de muitas maneiras.

Assim como os fragmentos de Estesícoro, o romance expõe cenas cruzadas, flashes na vida de um monstro, desde a infância até a idade adulta. Gerião agora não tem mais três corpos - mas éainda vermelho e tem asas. Viverá um intenso romance adolescente com o jovem Héracles e por ele será abandonado. Já adulto, Gerião vai a Buenos Aires, onde, por acaso, reencontra Héracles, que a essa altura viaja pela América do Sul com seu namorado, Ancash, gravando o som de vulcões: para um documentário sobre Emily Dickinson. Gerião e Héracles são seus leitores, evocam seus versos. E o título do penúltimo capítulo do livro é: "Fotografias: \# 1748" (AoR 145).

Entre as inumeráveis ressonâncias de Emily Dickinson no livro de Carson, propus me concentrar numa única: mostrar como o poema n.

26 "Volcanoes be in Sicily/ And South America/ I judge from my Geography-/ Volcanos nearer here/ A Lava step at any time/ Am I inclined to climb - / A Crater I may contemplate/ Vesuvius at Home." (DICKINSON, 1960, n. 1705, p. 694).

27 "[...] I guess I'm someone who will never be satisfied,/ said Herakles. Geryon felt all nerves in him move to the surface of his body./ What do you mean satisfied?/ Just-satisfied. I don't know. From far down the freeway came a sound/ of fishhooks scraping the bottom of the world" (AoR 44). 
1748 participa de uma forma quase paradoxal de atenção aos fatos, que reconheço na escrita poética de Anne Carson, aí imbricadas as suas atividades leitoras e tradutórias. Estamos finalmente em condições de ir diretamente ao ponto.

Começo por uma passagem extraída de um corpo-extra do livro-monstro de Anne Carson, um corpo a mais de que ainda não tinha falado aqui: trata-se de uma seção acrescentada ao final, sob o título "Entrevista (Estesícoro)" (AoR 147-149). Traz uma conversa entre um "I" (que em inglês pode dizer "eu" ou abreviar "Interviewer" [entrevistador]) e um "S" (indicando, claro, "Stesichoros", mas também, como a entrevista dará a ver, "Stein", Gertrude Stein). A entrevista se abre com as seguintes palavras de "I", ditas num fluxo que mantém a (falta de) pontuação com que já vínhamos convivendo antes:

Há um crítico que vê na sua obra uma espécie de teatro da ocultação um interesse especial em descobrir o que fazem ou como agem as pessoas quando sabem que estão sendo privadas de informações importantes talvez isso tenha a ver com uma estética da cegueira ou mesmo com um desejo de cegueira [...]..$^{28}$

Podemos nos perguntar: como poderia um desejo de cegueira ligar-se aos atos daqueles que se sabem privados de informações importantes? E como poderia um desejo assim associar-se a alguma forma de atenção aos fatos?

O paradoxo cede um pouco - torna-se, quem sabe, um quase paradoxo - se consideramos uma outra entrevista, dessa vez concedida pela própria Anne Carson (D'AGATA; CARSON, 1997, p. 13): ela nos diz ali que os fatos são "um substituto para a narrativa" e que, se os fatos lhe são úteis, é porque ela não tem "história alguma na cabeça". Escrever com fatos e sem histórias não coincide aqui, no entanto, com um desejo de "imitar a realidade", de prover-lhe uma imagem objetiva; Carson nos diz que é antes algo próximo de abarcar "um andamento musical", de surpreender "um movimento no interior de um evento ou de uma coisa" (p. 13).

Desmanchando a insidiosa (quase supersticiosa) lógica de sujeito e objeto com que costumamos entender o que significa "atentar aos fatos", ela nos diz ainda, em resposta a uma pergunta do entrevistador sobre o

28 "One critic speaks of a sort of concealment drama going on in your work some special interest in finding out what or how people act when they know that important information is being withheld this might have to do with an aesthetic of blindness or even a will to blindness if that is not a tautology [...]" (AoR 147). 
elemento autobiográfico em seus escritos, sobre o "eu" que ali comparece: "é só uma parte dos fatos no mundo [...] eu sou um conjunto de fatos, o rio é outro conjunto de fatos e esses degraus são um outro conjunto - trata-se de usá-los todos de algum jeito democrático" (D’AGATA; CARSON, 1997, p. 18).

O desejo de cegueira poderia aqui ser compreendido como um desejo de perder o ponto de vista, de desincumbir-se do encargo de ser a sede unilateral da operação visiva: isso coincidiria de alguma forma com uma disposição para afrontar o autoritarismo narrativo, os impulsos monárquicos do sujeito em sua insistência de contar por si a história do objeto - impulsos que podem talvez ceder se, de algum jeito democrático, esse sujeito puder se reconhecer apenas como um conjunto de fatos, no sentido de Carson: um entre outros (voláteis) conjuntos de fatos.

Isso nos devolve ao poema de Emily Dickinson: vive a natureza humana sem quem a venha escutar? A certa altura do romance, Carson se entrega a essa pergunta. Escreve de volta a Emily Dickinson, com este verso:

[...] a realidade é um som é preciso entrar em sintonia com ela não ficar aos gritos. ${ }^{29}$

No versos de Dickinson e de Carson, um convite a abrir mão do centro, a sugestão de uma vida menos envolvida com seu próprio som e mais atenta ao som ao redor - algo que faz lembrar também a atenção multiplicada de Estesícoro na versão monstruosa que dá para a vida do monstro Gerião.

A possibilidade de uma vida que não grita com a realidade, que não busca submetê-la o tempo todo a sua tagarelice, parece desenhar-se no conjunto de poemas com que Carson compõe o seu romance.

Logo de início surpreenderemos um Gerião criança "trabalhando na sua autobiografia”, que nesse momento vem a ser uma escultura: está colando um cigarro num tomate, ao que depois acrescenta, a título de cabelo, tiras rasgadas do papel rugoso que encontrara na carteira da mãe. Tomate, cigarro e papel rasgado (que ainda não é dinheiro) são parte de uma autobiografia - tudo no livro parece conspirar para que a cena indique menos a autorrepresentação rudimentar e infantil de um sujeito

29 "Reality is a sound, you have to tune in to it not just keep yelling." (AoR 6o). 
e mais uma (democrática) reunião com conjuntos de fatos. Essa é uma autobiografia que é um modo de estar com as coisas, entre as coisas.

Mas "não há no mundo palavras para um mundo sem self, visto com clareza impessoal". ${ }^{\circ}$ A frase sai de um livro de autoajuda intitulado Esquecimento: o preço da sanidade?, que um Gerião agora adulto lê num quarto de hotel, logo depois de ter deixado de lado o "maligno" Walt Whitman. A objeção de plantão não é refutada: é explicitada com a ironia fina (e caracteristicamente órfã de certezas) que atravessa o livro. Em uma passagem de Plainwater lemos algo que vai na mesma direção:

Ele disse: "Pense na diferença entre acreditar no que se quer acreditar e acreditar no que pode ser provado". Pensei sobre aquilo. "Não quero acreditar em nada", eu disse. (Mas estava mentindo) "E não tenho nada a provar." (Mentindo de novo) "É só que eu gosto de andar pelo mundo e parar, notando alguma coisa sob o céu." (Já isso é verdade). (CARSON, 200ob, p. 117)

Um gosto por "topar com as coisas” parece simplesmente dar as costas aos já cansados embaraços da verdade e da mentira, os quais, sempre com humor, não deixam de ser reconhecidos.

Muito importante para o ponto específico que move este artigo é notar que esse "topar com as coisas" acomoda, nas encenações de Carson em Autobiography of Red, a própria escrita. A linguagem é ali submetida ao mesmo tipo de horizontalidade com que se deflaciona o sujeito falante. Lembremos da caixa democrática de Estesícoro, contendo pedaços de carne, letras de música, notas de palestra. No romance em verso, essa relação horizontal entre o verbal e o não verbal virá explícita em inúmeras (e belas) ocasiões:

A palavra cada soprava na sua direção e se desfazia no vento. Gerião tinha sempre tido esse problema: uma palavra como cada, quando ele a fitava, desfazia-se nas suas letras e ia embora.

Ficava um espaço para o significado, mas em branco.

Dava para achar as letras penduradas por ali em galhos ou na mobília ${ }^{31}$

[Geriao e Héracles] reconheceram-se como itálicos.32

30 "There are no words for a world without a self, seen with impersonal clarity." (AoR 107). 31 "The word each blew towards him and came apart on the wind. Geryon had always/ had this trouble: a word like each,/ when he stared at it, would disassemble itself into separate letters and go./ A space for its meaning remained there but blank./ The letters themselves could be found hung on branches or furniture in the area." (AoR 26).

32 "[...] recognized each other like italics" (AoR 39). 
Ele tinha estado ali antes, balançando

dentro da palavra "Ela" como um enfeite pendurado num cinto. [... $]^{33}$

Água! De entre duas massas agachadas do mundo a palavra saltou. ${ }^{34}$

Entre as estratégias empregadas por Carson para, à maneira de Estesícoro, liberar as travas da linguagem, entre seus modos de responder à fúria contra o clichê, está então essa espécie de democracia na qual as próprias palavras vão sendo incluídas entre os fatos com que podemos "topar" ao andar pelo mundo.

$\mathrm{Na}$ entrevista que mencionamos há pouco, Carson afirma que um fato "é uma oferta do mundo" e que escrever um ensaio ou um poema (uma tradução, eu acrescentaria) é fazer alguma coisa com esse fato - é "fazer uma oferta de volta ao mundo ou a alguém" (D'AGATA; CARSON, 1997, p. 17). Parece ser isso exatamente o que ela faz com Estesícoro, Emily Dickinson, Gertrud Stein e muitos dos outros "pedaços de carne" que traz à caixa da sua própria (re)escrita.

Isso nos permite voltar à pergunta: como agem aqueles que sabem que estão sendo privados de informações importantes? Pensada no âmbito da escrita, essa pergunta poderia lembrar talvez a cena hermenêutica. E a resposta óbvia seria: tentam obtê-las, tentam descobrir o segredo (ou, diriam os menos otimistas, resignam-se diante da impossibilidade de descobri-lo). Mas em Carson, com Dickinson, desloca-se o motivo do segredo. Se os escritos são, no emprego particular que Carson dá à palavra, fatos, e, se fatos são uma oferta, trata-se então de escrever de volta, fazer uma espécie de contraoferta. E escrever de volta nada tem a ver com desvelar segredos, muito ao contrário.

Num dos poemas finais de Autobiography of Red, ao flagrar pela primeira vez as asas de Gerião, Ancash lhe conta uma antiga lenda, corrente entre os habitantes de uma aldeia chamada Jucu: seus ancestrais eram adoradores do vulcão e costumavam jogar lá dentro alguns iniciados, para testar a sua sabedoria; os verdadeiros sábios seriam aqueles que conseguiam voltar - agora vermelhos, alados e imortais, queimadas no vulcão todas as suas fraquezas. Enquanto ouve a fantástica história, Gerião começa a se coçar furiosamente nas asas,

33 "He had been here before, dangling/ inside the word she like a trinket at a belt." (AoR 57). 34 "Water! Out from between two crouching masses of the world the word leapt" (AoR 70). 
atacado pelos piolhos que infestavam o cobertor que ele tinha sobre os ombros (AoR 128). Essa aliança entre o fantástico e o prosaico atravessa o livro. Um Gerião vermelho e alado esteve o tempo todo circulando entre os demais - num bar em Buenos Aires ouve a certa altura uma cantora de tango: "Quem um monstro pode culpar por ser vermelho?" (AoR 104).35

$\mathrm{O}$ vulcão reticente, a véspera da lava, seu plano sempre desperto, está também desde sempre ali: em casa. Lemos ao final do romance em verso:

Somos seres incríveis,

Gerião está pensando. Somos vizinhos do fogo. ${ }^{36}$

Que sejam ininteligíveis os fatos surpreendidos nessa vizinhança não diminui ao oferta que fazem - muito ao contrário. Se resistem a integrarse, por exemplo, à narrativa linear é porque nela "há palavras demais, há um excesso de palavras que simplesmente não são os fatos" (perdemos os fatos quando ficamos "ocupados demais em passar de um fato ao outro por métodos convencionais: e; mas; oh não;”) (D’AGATA; CARSON, 1997, p. 14).

Ao renunciar à narrativa linear, por seus caminhos tão particulares, Carson está assim atentando aos fatos - pois são fatos, não segredos, as coisas que ali não se deixam integrar. Por exemplo, andamentos musicais, movimentos no interior de uma coisa ou de um evento.

$E$, entre esses conjuntos de fatos, na vizinhança de um rio, dos degraus de uma escada, de um vulcão: fragmentos de Estesícoro, um poema de Emily Dickinson, a obra de Gertrud Stein. Traduzi-los, lê-los, escrever com eles é também uma forma de atentar aos fatos, à oferta que fazem. E é comprometida com essa atenção que, ao propor-lhes uma contraoferta, ao lhes escrever de volta, Anne Carson afronta os clichês da leitura, da escrita e da tradução, dando ao seu livro, como vimos, uma feição monstruosa. Ela nos mostra, como poucos, que criar monstros pode ser uma forma de responder aos fatos.

35 "Who can a monster blame for being red?" (AoR 104).

36 "We are amazing beings,/ Geryon is thinking. We are neighbors off fire" (AoR 146). Interessante observar aqui que a edição dos poemas completos de Dickinson recentemente organizada por Cristanne Miller traz do variorum uma versão diferente para o penúltimo verso do poema que traduzi aqui: em vez de "the only secret people keep", "the only secret neighbors [vizinhos] keep” (DICKINSON, 2016, p. 687). Não sei se Carson terá consultado o variorum, mas é notável a coincidência. 


\section{WRITING BACK: ANNE CARSON, EMILY DICKINSON}

Abstract: Anne Carson is a poet, essayist, translator, and professor of Classics. One of the acclaimed forces of her published work is its singular ability to combine acts of writing that are normally distributed amongst these different occupations. With unlikely freedom and exactness, her works mingle poetry, translation, essay, scolio, literary criticism, lecture, libretto, interview and more. It is indeed an oeuvre that embodies in admirable manner the now much discussed reciprocity between writing, reading and translating. This article reflects upon the ways this happens in Autobiography of Red: A Novel in Verse. I explore the hypothesis that a quasi-paradoxical attention to facts presides over the gestures of reading, translating, and poetic writing that Carson enacts and imbricates in this unclassifiable book. Special emphasis is given to an Emily Dickinson poem Carson uses as the novel's epigraph: it is with a translation of this poem that I open my reflection here.

Keywords: Anne Carson; Emily Dickinson; Translation.

\section{REFERÊNCIAS}

BEASLEY, Bruce. Who Can a Monster Blame for Being Red? Three Fragments on the Academic and the Other in Anne Carson's Autobiography of Red. In: WILKINSON, Joshua M. (Ed.). Anne Carson: Ecstatic Lyre. Ann Arbor, MI: University of Michigan Press, 2015, pp. 74-81.

CAMPBELL, David. Greek Lyric: Stesichorus, Ibycus, Simonides, and others. Cambridge, MA: Harvard University Press, 1991.

CARSON, Anne. Autobiography of Red: A Novel in Verse. New York: Alfred A. Knopf, 1998.

CARSON, Anne. Plainwater. Nova York: Alfred A. Knopf, 2000.

CARSON, Anne. Eros the Bittersweet. Champaign/Londres: Dalkey Archive Press, 2015a.

CARSON, Anne. the task of the translator of antigone. In: Sófocles. Antigonick. Trad. Anne Carson. Nova York: New Directions, 2015b, pp. 3-6.

CARSON, Anne. Variations on the Right to Remain Silent. In: Float. London: Jonathan cape, 2016.

D'AGATA, John; CARSON, Anne. A with Anne Carson. The Iowa Review, v. 27, n. 2, 1997, pp. 1-22. Disponível em: <http://ir.uiowa.edu/iowareview/vol27/iss2/2>. Acesso em: 2 fev. 2018.

DICKINSON, Emily. The Complete Poems of Emily Dickinson. Ed. Thomas H. Johnson. Boston/Toronto: Little, Brown and Company, 1960.

DICKINSON, Emily. Emily Dickinson's Poems as She Preserved Them. Ed. Cristanne Miller. Massachusetts/Londres: Cambridge/Harvard University Press, 2016. 
WATCHEL, Eleanor; CARSON, Anne. An Interview with Anne Carson. Brick: A Literary Journal, n. 89, 2014, [s.p.]. Disponível em: <https://brickmag.com/an-interviewwith-anne-carson/>. Acesso em: 10 jan. 2018.

DERRIDA, Jacques. Le monolinguisme de l'autre - ou la prothèse d'origine. Paris: Galilée, 1996.

NANCY, Jean-Luc. Fazer, a poesia. Trad. Letícia D. G. de França, Janaina Ravagnoni e Mauricio M. Cardozo. Alea, Rio de Janeiro, v. 15, n. 2, 2013, pp. 414-422.

SÓFOCLES. Antigonick. Trad. Anne Carson. Nova York: New Directions, 2015.

STEINER, George. Anne Carson "translates" Antigone. The Times Literary Supplement, August 1, 2012, [s.p.].

WILKINSON, Joshua M. (Ed.). Anne Carson: Ecstatic Lyre. Ann Arbor, MI: University of Michigan Press, 2015. 